\title{
MACHINING OF NICKEL ALLOY BY CUTTING TOOL WITH PREPARED CUTTING EDGE PREPARATION
}

\author{
Tomáš ZLÁMAL, Šárka MALOTOVÁ, Tomáš SZOTKOWSKI, Ondřej VORTEL, Antonín TREFIL \\ VSB - Technical University of Ostrava, Ostrava, Czech Republic, EU, tomas.zlamal@vsb.cz, \\ sarka.malotova@vsb.cz, tomas.szotkowski.st@vsb.cz, ondrej.vortel@vsb.cz, antonin.trefil@vsb.cz
}

https://doi.org/10.37904/metal.2019.957

\begin{abstract}
The article deals with machining and development of the wear of cutting tools for turning of nickel alloy Inconel $718-2.4648$. This alloy is characterized by high strength and toughness, low thermal conductivity and high abrasion. As a result of these properties, the alloy has worsened machinability and it is necessary to put emphasis on technology, a choice of cutting tools, their geometry and cutting conditions. The exchangeable cutting inserts marked VBMT 160402F-1, made from sintered carbide and pre-verified cutting conditions were used for machining of the alloy. The microgeometry of cutting tools was defined with brushing technology and abrasive jet machining technology. The edge radius $r_{n}=20 \pm 5 \mu \mathrm{m}$ on cutting inserts was created by the brusher with abrasive corundum particles and the edge radius $r_{n}=20 \pm 5$ and $35 \pm 5 \mu \mathrm{m}$ was created by abrasive jet machining technology. A gradual wear development and its intensity was checked during turning process of Inconel 718 with the use cutting tools with rectified cutting edge. Depending on intensity of a wear on major flank was determined a tool-life of cutting inserts and an influence of the microgeometry on machining process of alloy was considered.
\end{abstract}

Keywords: Wear, nickel alloy, Inconel, cutting tools, microgeometry

\section{INTRODUCTION}

Today, higher requirements put emphasis on material properties and life time of machine components working in extreme conditions exposing to e.g. cosmic, energy and chemical industry. It is possible to classify these materials into category superalloys based on nickel, cobalt, titanium and its alloys. Superalloys are characterized by increased strength, oxidation and corrosion resistant and high-temperature creep. With relation to these properties' superalloys are characterized by worse durability during machining. Hence, a cutting tool is exposed large mechanical and thermal load, therefore it is important to select suitable machining process, cutting tool and its material, geometry, microgeometry and cutting conditions [1,2].

Checkable and predictable machining process is possible to guarantee selecting of suitable microgeometry of cutting edge. One of variants is a rectification of cutting edge with mechanical methods of cutting edge preparation (polishing, brushing, drag finishing, abrasive (water) jet machining etc.) The aim of these methods is a removal of undesirable unevenness and defects in area of cutting edge for the purpose of achieving higher surface quality before and after coating and higher cuttability. Required size and shape of cutting edge radius is ensured by suitable technology of mechanical method of cutting edge surface preparation with regards on kind of machined material and machining parameters $[3,4]$.

A shape of cutting inserts plays big role on machining process and wear of cutting tool. The authors Thellaputta, G. R. et al. [5] in their contribution Machinability of Nickel Based Superalloys: A Review describe an influence of cutting edge shape on durability and machining process of nickel alloy. In contribution they mention about the influence of tip angle $\varepsilon_{r}$ on relative strength of cutting edge, higher durability and better quality of machined surface. Then, a team of authors Ezugwu, E. O. et al. [6] in article The machinability of nickel-based alloys evaluated process and development of cutting tool wear for machining of nickel alloy of influence of intensive mechanical and thermal load. High stress and heat in area of cutting edge influence an intensity of wear and 
its durability during machining of nickel alloys. Very often wear is abrasive flank wear, rake wear, notch wear and edge chipping with breakage of cutting inserts.

\section{EXPERIMENTAL ACTIVITY}

Experimental part is focused on turning of nickel alloy marked according W. Nr. 2.4648 (Inconel 718). The alloy is characterized by high strength and toughness, low thermal conductivity and high abrasive resistant. Exchangeable cutting inserts of rhombic shape with sharp positive cutting geometry made from sintered carbide and marked VBMT 160402-f1 were used for machining, see Figure 1.

Cutting edge preparation was carried out with the aim removal of defects, formation of rounded edge and required surface microgeometry for coating technology. Cutting edge radius $r_{n}=20 \pm 5 \mu \mathrm{m}$ was achieved with brushing technology. The process was realized with the used brush with rectangular cross-section of nylon fibers, which contained hard corundum

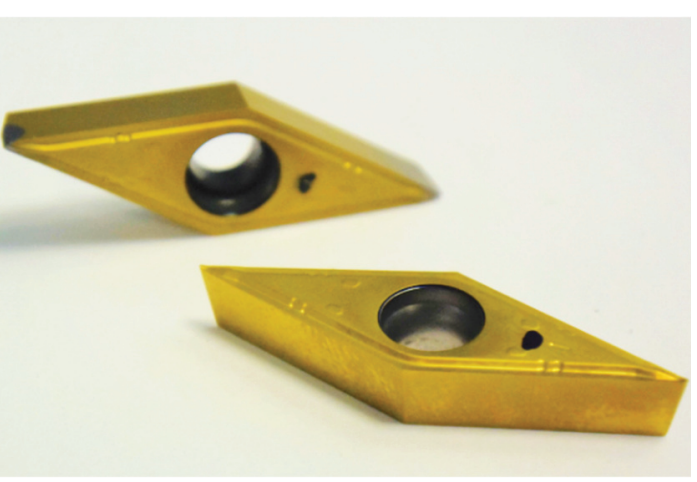

Figure 1 Cutting inserts of rhombic shape for machining nickel alloy particles marked $80 \mathrm{SiC}$. Fiber shape, size and type of particles was determined with regards on a cutting edge radius. Cutting inserts marked C1 - C4 were made by brushing technology.

Abrasive jet machining technology was used for cutting edge preparation with cutting edge radius $r_{n}=20 \pm 5$ $\mu \mathrm{m}$ (cutting inserts marked $\mathrm{A}$ ) and with cutting edge radius $r_{n}=35 \pm 5 \mu \mathrm{m}$ (cutting inserts marked E). Principle of abrasive jet machining is effect of blast media mixture (pink $\mathrm{Al}_{2} \mathrm{O}_{3}, 240$ mesh) and water with the used highpressure air. Cutting edge radius and shape of tested samples was measured by optical microscope Alicona Infinite Focus G5. The results are shown in Table 1 and Figure 2. Better cuttability, but lower strength of edge is expected for sharper geometry. For that reason, it is necessary to select a correct combination of cutting conditions with regards on cutting edge radius.

Parameter $R a$ is average arithmetic deviation of the assessed profile defined on the sampling length. Parameter $R z$ is maximum height of the profile defined on the sampling length. Factor $K$ defined to describe the symmetry of the contour generated by the cutting edge rounding process.

Table 1 Cutting geometry of used inserts

\begin{tabular}{|c|c|c|}
\hline \multicolumn{2}{|c|}{ Tested cutting inserts - VBMT 160402-F1 } \\
\hline Brushing 80SiC & \multicolumn{2}{|c|}{ Abrasive jet machining B-Graf } \\
\hline$r_{n}=20 \pm 5 \mu \mathrm{m}-$ sample C & $r_{n}=20 \pm 5 \mu \mathrm{m}$ - sample A & $r_{n}=35 \pm 5 \mu \mathrm{m}$ - sample $\mathrm{E}$ \\
\hline$r_{n}=17.3 \mu \mathrm{m}$ & $r_{n}=17.77 \mu \mathrm{m}$ & $r_{n}=41.97 \mu \mathrm{m}$ \\
\hline$\alpha_{o}=5.1^{\circ}$ & $\alpha_{o}=5.2^{\circ}$ & $\alpha_{o}=5.1^{\circ}$ \\
\hline$\beta_{o}=68.2^{\circ}$ & $\beta_{o}=70.7^{\circ}$ & $\beta_{o}=86.2^{\circ}$ \\
\hline$Y_{o}=16.8^{\circ}$ & $Y_{o}=14.1^{\circ}$ & $Y_{o}=-1.3^{\circ}$ \\
\hline$K=0.08$ & $K=1.44$ & $K=1.59$ \\
\hline$R a=0.54 \mu \mathrm{m}$ & $R a=0.25 \mu \mathrm{m}$ & $R a=0.23 \mu \mathrm{m}$ \\
\hline$R z=2.03 \mu \mathrm{m}$ & $R z=1.21 \mu \mathrm{m}$ & $R z=0.97 \mu \mathrm{m}$ \\
\hline
\end{tabular}



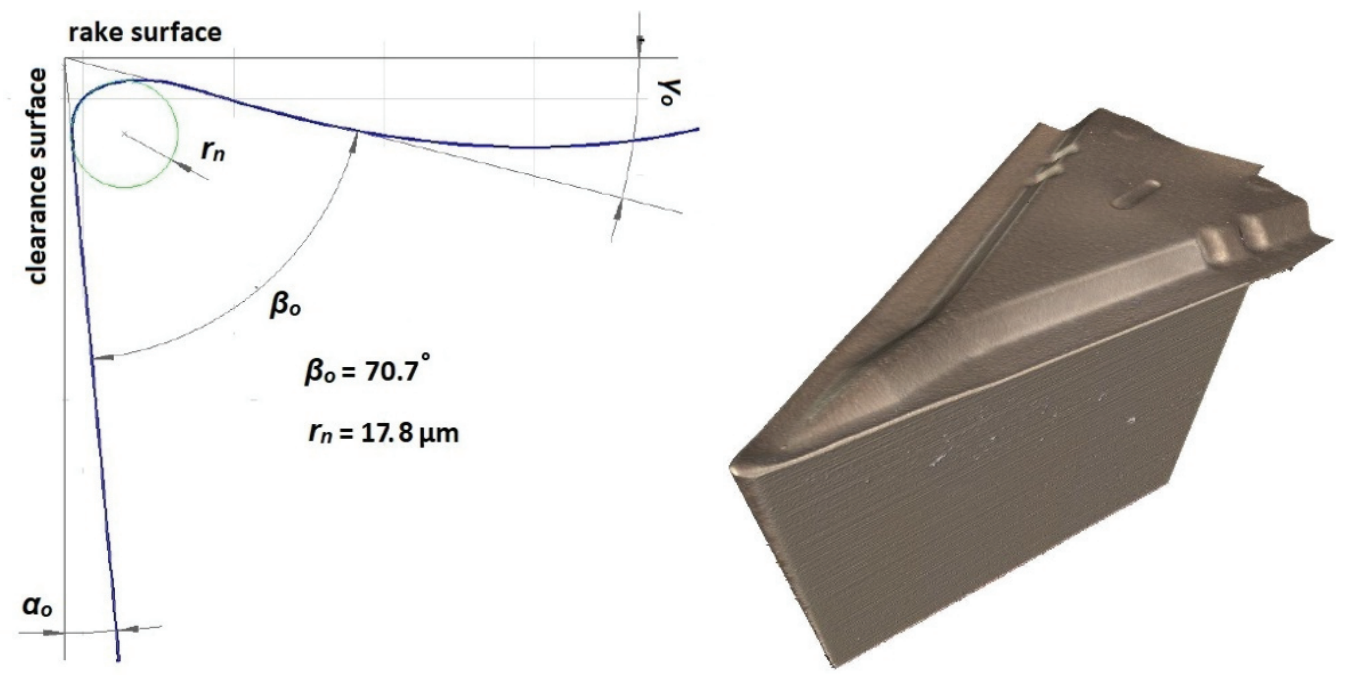

Figure 2 Geometry of cutting inserts

Cutting conditions were selected based on properties of machined material, cutting material and its geometry and working environment. For machining of nickel alloy lower range of cutting conditions are recommended due to high heat and a mechanical load. In first testing phase, cutting conditions were selected based on a recommendation of cutting producer. High value of feed caused accelerated wear process and early end of tests due to of tip breakage. Therefore, a modification of cutting conditions was carried out with their ensuing verification. Cutting conditions for machining of nickel alloy were:

- $\quad$ cutting speed $v_{c}=50 \mathrm{~m} \cdot \mathrm{min}^{-1}$,

- $\quad$ feed $f=0.07 \mathrm{~mm}$,

- $\quad$ cutting depth $a_{p}=2 \mathrm{~mm}$.

\section{EVALUATION OF WEAR PROGRESS AND RESULTS}

Wear progress and development of exchangeable cutting inserts made from sintered carbide was tracked during machining of nickel alloy W. Nr. 2.4648. Wear intensity of cutting inserts was measured on the basis of direct microscopic method on major flank of cutting tool. Durability 30 minutes was determined for machining alloy under predetermined cutting conditions. Value of wear criterion was determined $0.2 \mathrm{~mm}$ for the reason of expected wear and security of machining process. Notch wear in distance corresponding with approximately cutting depth and abrasive wear was created during turning of nickel alloy W - Nr. 2.4648 for all cutting inserts, see Figure 3.

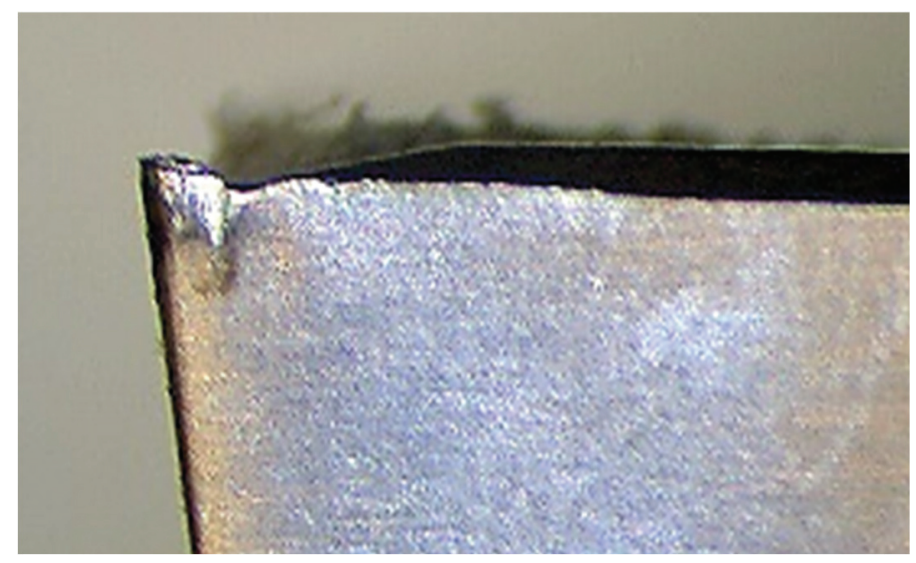

Figure 3 Notch wear 
Cutting inserts marked $C$ and $A\left(r_{n}=20 \pm 5 \mu \mathrm{m}\right)$ had very fast wear regardless of mechanical method of cutting edge preparation and by influence of intensive mechanical load came about tip breakage, see Table 2.

Table 2 Wear development of cutting edge rounded with brushing $r_{n}=20 \pm 5 \mu \mathrm{m}$

\begin{tabular}{|c|c|c|c|}
\hline \multicolumn{3}{|c|}{ Brushing (80SiC) $r_{n}=20 \pm 5 \mu \mathrm{m}$ - sample C2 } \\
\hline$t_{A s}(\mathrm{~min})$ & Rake surface $A_{Y}$ & Major Clearance surface $A_{\alpha}$ & Minor Clearance surface $A^{\prime}{ }_{\alpha}$ \\
\hline 2 & & & \\
\hline
\end{tabular}

Machining process was ended early then value of wear criterion and required durability 30 min was achieved. Visible weakening of cutting edge and intensive mechanical load was the cause of tip breakage, see Figure 4. Wear progress and measured values of durability for all tests are shown in Table $\mathbf{3}$.
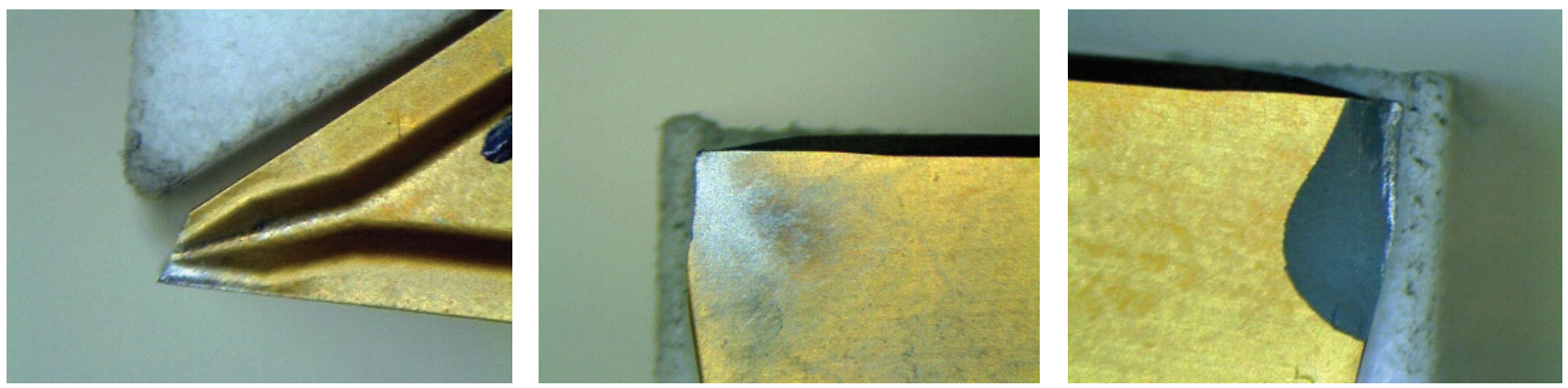

Figure 4 Tip breakage of cutting edge $-r_{n}=20 \pm 5 \mu \mathrm{m} ; t_{A s}=1.16 \mathrm{~min}$ 
Table 3 Wear development of cutting edge rounded with mechanical method of cutting edge preparation

\begin{tabular}{|c|c|c|}
\hline Brushing $80 \mathrm{SiC}$ & \multicolumn{2}{|c|}{ Abrasive jet machining B-Graf } \\
\hline$r_{n}=20 \pm 5 \mu \mathrm{m}$ & $r_{n}=20 \pm 5 \mu \mathrm{m}$ & $r_{n}=35 \pm 5 \mu \mathrm{m}$ \\
\hline \multicolumn{3}{|c|}{ Durability of cutting inserts $t_{A s}(\mathrm{~min})$} \\
\hline $\mathrm{C} 1=6 \mathrm{~min}$ & $\mathrm{~A} 1=1.2 \mathrm{~min}$ & $\mathrm{E} 1=30 \mathrm{~min}$ \\
\hline $\mathrm{C} 2=28 \mathrm{~min}$ & $\mathrm{~A} 2=2.1 \mathrm{~min}$ & $\mathrm{E} 2=30 \mathrm{~min}$ \\
\hline $\mathrm{C} 3=5.6 \mathrm{~min}$ & $\mathrm{~A} 4=1.8 \mathrm{~min}$ & \\
\hline \multirow[t]{2}{*}{$\mathrm{C} 4=12.8 \mathrm{~min}$} & $\mathrm{~A} 5=20.6 \mathrm{~min}$ & \\
\hline & $\mathrm{A} 6=23.5 \mathrm{~min}$ & \\
\hline
\end{tabular}

Influence of cutting edge radius on wear resistance became evident for cutting tools with edge radius $r_{n}=35 \pm 5$ $\mu \mathrm{m}$ made by abrasive jet machining. In this case, flank wear did not overrun the value of critical wear and this test was ended due to achievement of required durability $30 \mathrm{~min}$. Cutting inserts with larger cutting edge radius in compare with cutting edge radius $r_{n}=25 \pm 5 \mu \mathrm{m}$ have higher relative strength and better tolerated mechanical load. Influence of cutting edge radius $\left(r_{n}=35 \pm 5 \mu \mathrm{m}\right)$ on machining process, wear progress and higher durability was proven during machining with samples E1 and E2, see Table 4.

Table 4 Wear development of cutting edge rounded with abrasive jet machining $r_{n}=35 \pm 5 \mu \mathrm{m}$

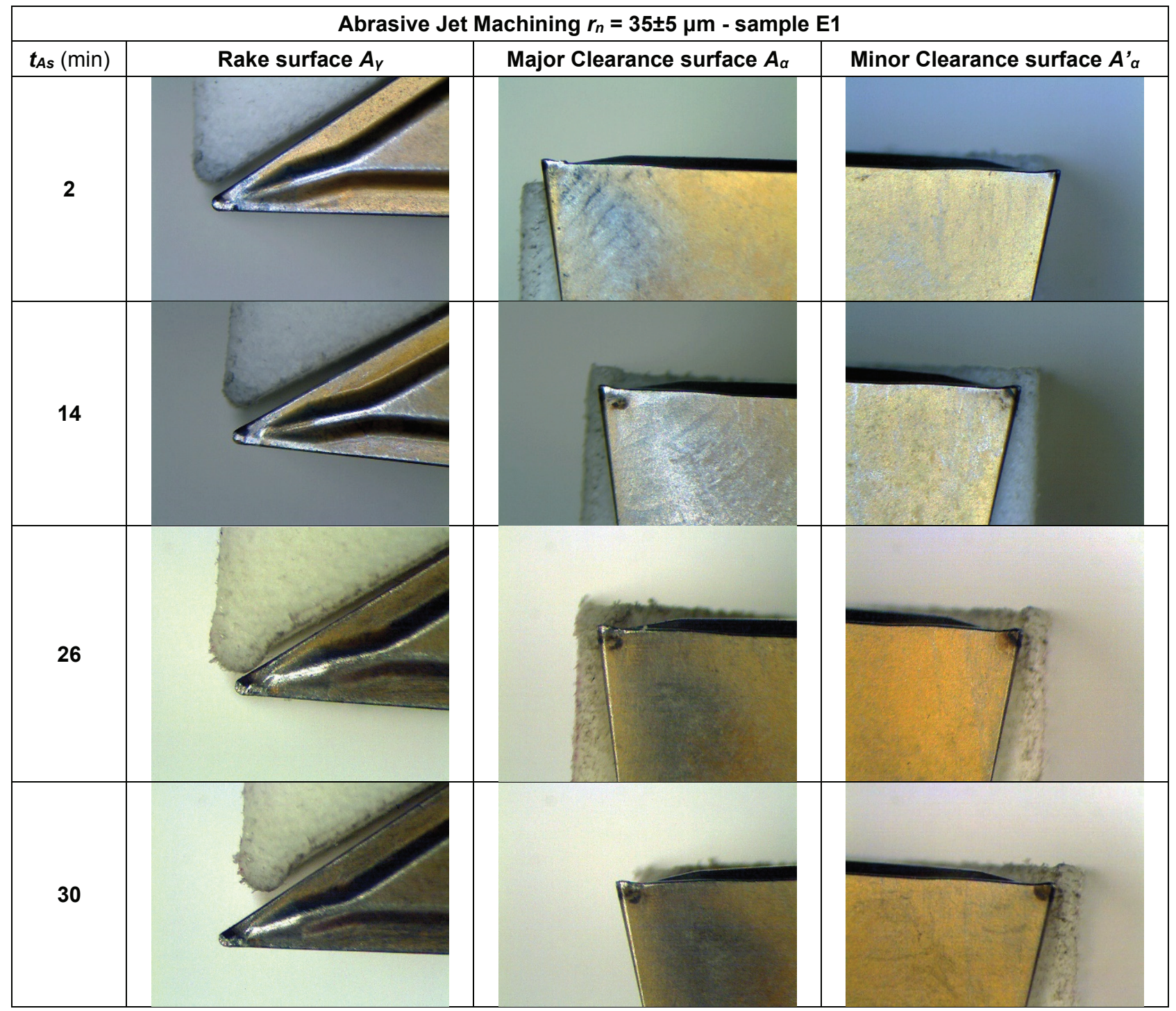


In both cases, despite lower surface roughness of cutting inserts, abrasive flank wear, rake wear and attaching of machined material layers was seen on cutting edge, see Figure 5. It follows that surface roughness of cutting inserts did not influence durability of cutting tools during machining of nickel alloy W. Nr. 2.4648.
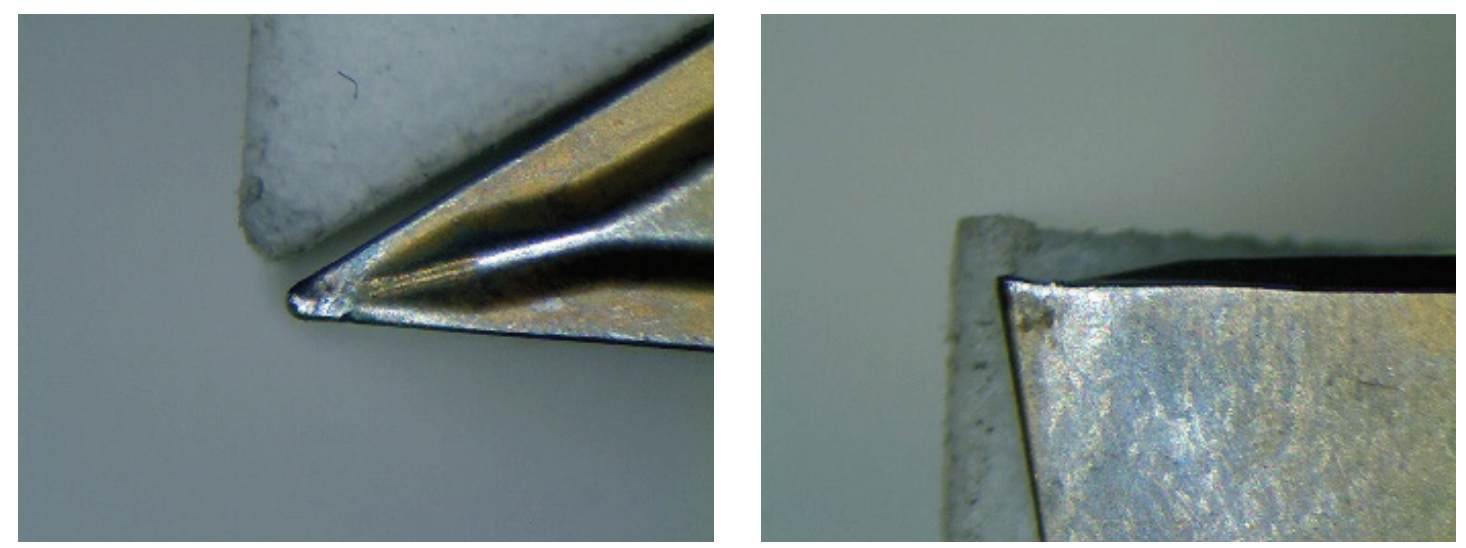

Figure 5 Cutting inserts after abrasive jet machining $r_{n}=35 \pm 5 \mu \mathrm{m}-t_{A s}=20 \mathrm{~min}$

The chart (Figure 6) was constructed for comparison the both technologies of mechanical surface method, which describes machining time dependence on cutting edge radius. Despite better surface roughness, set of samples cutting inserts with edge radius $r_{n}=20 \pm 5 \mu \mathrm{m}$ for abrasive jet machining technology achieved the lowest durability. On the other side, the best results were achieved for larger edge radius for the same technology of mechanical method.

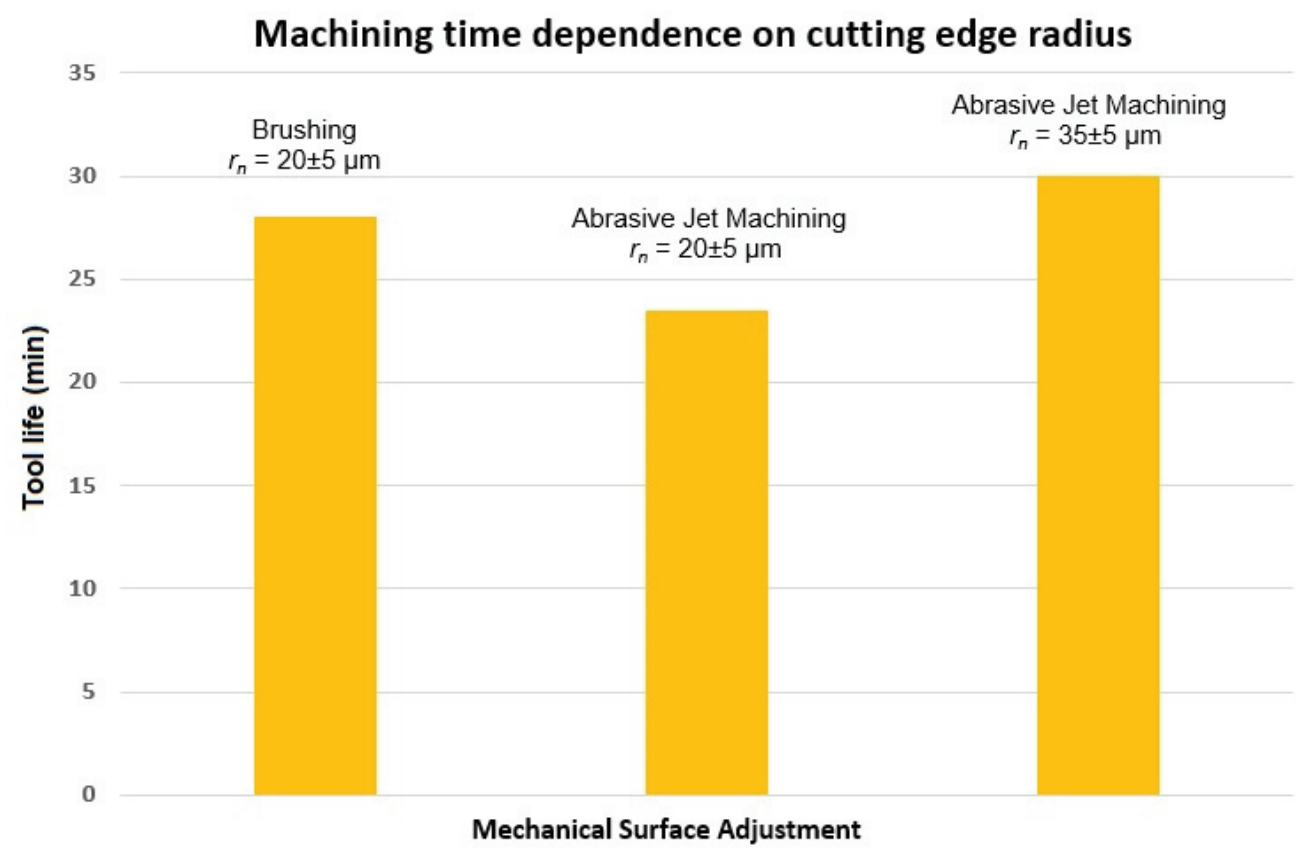

Figure 6 Machining time dependence on cutting edge radius

\section{CONCLUSION}

Article deals with machining and wear development of tailored cutting inserts during turning process of nickel alloy W. Nr. 2.4648. As a result of of specific properties of alloy, such as increased strength for high temperature, low thermal conductivity, high abrasive resistance, and thus worsened machinability, especially 
it is important to pay attention to a choice of cutting material, its geometry and cutting conditions. Exchangeable cutting inserts made from sintered carbide marked VBMT 160402-F1 and predetermined cutting conditions were used for machining nickel alloy. Cutting edge preparation was used for modification of cutting edge microgeometry removal of defects from surface of cutting tools, for rounding edge with defined shape and size and for treatment of surface roughness. Brushing technology (80SiC) and abrasive jet machining technology (B-Graf) were used for modification of microgeometry of cutting inserts. Both of these technologies ensure high accuracy and surface quality of cutting inserts.

Brushing technology was used for creation cutting edge with radius $r_{n}=20 \pm 5 \mu \mathrm{m}$ and cutting edge radius $r_{n}=$ $20 \pm 5$ and $35 \pm 5 \mu \mathrm{m}$ was created by abrasive jet machining technology. With regard to shape of cutting inserts with larger entering angle and small radius were used cutting conditions suitable for machining of nickel alloy $\mathrm{W}$ - Nr. 2.4648. During machining process intensive wear created as a result of the abrasion, notch wear and attaching of machined material layers. As a result, it was a weakening insert tip and decrease of relative tool strength. Tip breakage and early ending of test became evident during increased mechanical load for cutting inserts with edge radius $r_{n}=20 \pm 5 \mu \mathrm{m}$ regardless of used technology of cutting edge preparation. Similar progress of wear was tracked for cutting inserts with edge radius $r_{n}=35 \pm 5 \mu \mathrm{m}$. In addition, thin layers of machined material were attached on surface which kept protective function of cutting edge. Sufficient relative strength against mechanical load and required durability 30 min were guaranteed without achieving critical value of wear. It is necessary to select material of cutting tool with regard to its macro and microgeometry for ensuring right function of cutting tool (high cuttability and relative strength of cutting edge).

\section{ACKNOWLEDGEMENTS}

This work has been done in connection with projects Education system for personal resource of development and research in field of modern trend of surface engineering - surface integrity, reg. no. CZ.1.07/2.3.00/20.0037 financed by Structural Founds of Europe Union and from the means of state budget of the Czech Republic and by the Specific Research Project SP2019/60 financed by the Ministry of Education, Youth and Sports and Faculty of Mechanical Engineering VŠB-TUO.

\section{REFERENCES}

[1] RODRÍGUEZ, C.J.C. Cutting Edge Preparation of Precision Cutting Tools by Applying Micro-abrasive Jet Machining and Brushing. Kassel: Kassel Univ. Press. 2009. p. 386.

[2] ŠíMA, M. and JANKU゚, R. Mechanical treatment of monolithic cutting tools before PVD coatings. MM Industrial Spectrum [online]. Brno: 2007 [viewed 2019-05-07]. Available from:

https://www.mmspektrum.com/clanek/mechanicka-uprava-monolitnich-nastroju-pred-pvd-povlaky.html (in Czech)

[3] VOPAT, T., KURUC, M., SIMNA, V., NECPAL, M., BURANSKY, I. and ZAUJEC, R. The influence of cutting edge radius size on the tool life of cemented carbide drills. In: Proceedings of the 29th International DAAAM Symposium 2018. Vienna, 2018. pp. 0421-0425.

[4] DENKENA, B and BIERMANN, D. Cutting edge geometries. CIRP Annals. [online] 2014. vol. 63, iss. 2, p. 631653 [viewed 2017-05-01]. DOI: 10.1016/j.cirp.2014.05.009.

[5] THELLAPUTTA, G. R., PULCHARU SUBHASH BOSE and RAO, C.S.P. Machinability of nickel based superalloys: A review. Materials Today: Proceedings [online]. 2017. vol. 4, iss. 2, pp. 3712-3721 [viewed 2019-0506]. DOI: 10.1016/j.matpr.2017.02.266. Available from: https://www.sciencedirect.com/science/article/pii/S2214785317304765.

[6] EZUGWU, E.O., WANG, Z.M. and MACHADO, A.R. The machinability of nickel-based alloys: a review. Journal of Materials Processing Technology [online]. 1999. vol. 86, iss. 1-3, p. 1-16. [viewed 2019-05-06]. DOI: 10.1016/S0924-0136(98)00314-8. Available from: https://linkinghub.elsevier.com/retrieve/pii/S0924013698003148. 